\title{
Gadolinium Deposition in Brain: Current Scientific Evidence and Future Perspectives
}

\author{
Bang J. Guo', Zhen L. Yang ${ }^{2}$ and Long J. Zhang ${ }^{1,2 *}$ \\ 'Department of Medical Imaging, Jinling Hospital, Nanjing Clinical School, Southern Medical University, Nanjing, China, \\ ${ }^{2}$ Department of Medical Imaging, Jinling Hospital, Medical School of Nanjing University, Nanjing, China
}

In the past 4 years, many publications described a concentration-dependent deposition of gadolinium in the brain both in adults and children, seen as high signal intensities in the globus pallidus and dentate nucleus on unenhanced T1-weighted images. Postmortem human or animal studies have validated gadolinium deposition in these T1-hyperintensity areas, raising new concerns on the safety of gadolinium-based contrast agents (GBCAs). Residual gadolinium is deposited not only in brain, but also in extracranial tissues such as liver, skin, and bone. This review summarizes the current evidence on gadolinium deposition in the human and animal bodies, evaluates the effects of different types of GBCAs on the gadolinium deposition, introduces the possible entrance or clearance mechanism of the gadolinium and potential side effects that may be related to the gadolinium deposition on human or animals, and puts forward some suggestions for further research.

Keywords: gadolinium-based contrast agents, magnetic resonance imaging, T1 hyperintensity, gadolinium deposition, brain

\section{OPEN ACCESS}

Edited by:

Gianluca Serafini,

Ospedale San Martino (IRCCS), Italy

Reviewed by:

Mathias Hoehn,

Max-Planck-Gesellschaft (MPG),

Germany

Mehmet Emin Adin,

Tatvan Can Hospital, Turkey

*Correspondence:

Long J. Zhang

kevinzhlj@163.com

Received: 18 April 2018

Accepted: 27 August 2018

Published: 20 September 2018

Citation:

Guo BJ, Yang ZL and Zhang LJ

(2018) Gadolinium Deposition in Brain: Current Scientific Evidence and Future Perspectives.

Front. Mol. Neurosci. 11:335.

doi: 10.3389/fnmol.2018.00335

\section{INTRODUCTION}

Gadolinium-based contrast agents are widely used as CE-MRI agents for diagnosing or monitoring disease progress. In each year, over 30 million doses of GBCAs are consumed worldwide, and more than 300 million doses have been administrated since their introduction (Gulani et al., 2017). Clinically available GBCAs are all bonded by a ligand when they are used as an MRI contrast agent because free gadolinium is highly toxic (Rogosnitzky and Branch, 2016). Until 2006, all GBCAs were considered extremely safe. In 2006, a report (Marckmann et al., 2006) stated that some GBCAs may lead to NSF in patients with renal failure. However, when performing careful evaluation of the renal glomerular filtration rate before CE-MRI, new NSF cases have not been reported. Since 2013, the safety of GBCAs has attracted broad attentions over the world. A research group from Japan reported (Kanda et al., 2014) that signal intensity in the GP and DN on unenhanced T1 weighted imaging (T1WI) may be a result of the previous GBCAs administrations. This phenomenon leads to reconsideration of the safety of GBCAs. Following this report, many studies (Errante et al., 2014; McDonald et al., 2015; Miller et al., 2015; McDonald et al., 2017) focused on the potential risks of gadolinium retention in the human brain.

In this review, we summarize the current evidence on gadolinium deposition in the human and animal bodies, evaluate the effect of different types of GBCAs on the gadolinium deposition

Abbreviations: BBB, blood brain barrier; CE-MRI, Contrast enhanced magnetic resonance imaging; CSF, cerebrospinal fluid; DCN, deep cerebellar nuclei; DN, dentate nucleus; GBCAs, Gadolinium-based contrast agents; GP, globus pallidus; ICP-MS, inductively coupled plasma mass spectroscopy; NMOSD, neuromyelitis optica spectrum disorder; NSF, nephrogenic systemic fibrosis; RRMS, relapsing-remitting multiple sclerosis, T1WI, T1-weighted imaging. 
in brain, introduce the possible entrance or clearance mechanism of the gadolinium and potential side effects of gadolinium deposition in brain, and put forward some suggestions for further research.

\section{THE PHYSICOCHEMICAL PROPERTIES OF GBCAs}

Gadolinium is a paramagnetic material which can shorten the $\mathrm{T} 1$ relaxation time of living tissues. Based on the type of ligand and charge, the commercially available GBCAs can be classified into 4 different types (Frenzel et al., 2008): linear ionic, linear non-ionic, macrocyclic ionic, and macrocyclic non-ionic. Macrocyclic GBCAs form a rigid cage including a preorganized cavity for $\mathrm{Gd}^{3+}$ ion, while linear ligands form more flexible cages that wrap around the $\mathrm{Gd}^{3+}$ ion and are not fully closed. The differences in thermodynamic and kinetic stability of those ligands may be caused by their different chemical structures, whereby the non-ionic linear chelates are the least stable and the ionic macrocyclic chelates are the most stable (Dekkers et al., 2017). Table 1 gives the physicochemical properties of the commercially available GBCAs in current clinical practice.

\section{THE ASSOCIATION BETWEEN HIGH SIGNAL INTENSITY ON UNENHANCED T1WI AND PREVIOUS GBCAS ADMINISTRATIONS IN HUMAN}

T1-hyperintensity in the human brain is not a rare phenomenon. Many diseases such as multiple sclerosis (MS), Wilson disease, post-radiation therapy, hepatic encephalopathy (Roccatagliata et al., 2009; Kasahara et al., 2011, Kim et al., 2006; Rovira et al., 2008) etc., can lead to T1-hypeyintensity in deep gray matter. In the past 4 years, the correlation between previous GBCAs administrations and T1-hyperintensity in the deep brain has become a hot topic. Kanda et al. (2014) firstly described the T1-hypeyintensity in GP and DN may be caused by the previously repeated linear chelates GBCAs administrations. In this study, 19 adult patients with brain tumors previously receiving at least 6 doses of linear GBCAs (gadopentetate dimeglumine or gadodiamide) and 16 patients only receiving at least 6 unenhanced MRI without the GBCAs administrations were included. After calculating the mean signal intensity of the DN, GP, pons, and thalamus on unenhanced T1WI, T1-hyperintensity in deep gray matter nuclei only occurred in patients who previously exposed to GBCAs. The hyperintensity of DN and GP on unenhanced T1WI was associated with the number of previous GBCAs administrations independent on patients' renal function. In the same year, Errante et al. (Errante et al., 2014) found T1 hyperintensity of the DN was common in patients with brain metastases who had undergone multiple gadoliniumenhanced brain MRI. In this study, 37 patients with brain metastases and 38 patients with MS underwent at least 2 consecutive CE-MRI examinations, and the results showed there were a linear relationship between T1 hyperintensity and the number of CE-MRI scans in patients both with brain metastases and MS. Since then, many studies demonstrated that repeated administrations of various types of linear GBCAs were associated with T1-hyperintensity in the brain (Weberling et al., 2015; Ramalho et al., 2016b; Kuno et al., 2017; Zhang et al., 2017). Figure 1 shows a representative case with hyperintensity of the DN following repeated CE-MRI scans.

The same findings were also reported in pediatric patients. Roberts and Holden (2015) described a pediatric patient with repeated GBCAs administrations, progressive hyperintensity on unenhanced T1WI involving the DN and GP was observed. Similar phenomenon was also reported by others (Miller et al., 2015; Flood et al., 2016; Hu et al., 2016; Roberts et al., 2016a). Table 2 presents the current evidences of gadolinium deposition in pediatrics and adult brain.

\section{HISTOLOGICAL ANALYSIS CONFIRMED GADOLINIUM DEPOSITION IN HUMAN BRAIN}

The association between previous GBCAs administrations and T1 hyperintensity in DN and GP has been confirmed via human brain autopsy studies and animal studies. McDonald et al. (2015) compared the gadolinium contents of 23 (10 in contrast group and 13 in control group) deceased patients' $\mathrm{DN}$, pons, GP, and thalamus tissues by transmission electron microscopy, ICP-MS, and light microscopy. They found patients in the contrast group had $0.1-58.8 \mu \mathrm{g}$ gadolinium per gram of tissue with a significant dose-dependent relationship, which was consistent with changes of signal intensity on unenhanced T1WI. It seemed the gadolinium could pass the BBB and deposit in the capillary endothelium and neural interstitium in the patients from contrast group who had relatively normal renal function when undergoing MR examination. Kanda et al. (2015a) confirmed the gadolinium accumulation in the brain after analyzing brain samples of five subjects who received GBCAs (gadopentetate dimeglumine, gadodiamide, gadoteridol) and five subjects with no history of GBCA administrations by ICP-MS. They found the inner segment of the frontal lobe cortex, cerebellar white matter, GP, and frontal lobe white matter had the detectable level of gadolinium accumulation, while the DN and GP had the highest level of gadolinium deposition. McDonald et al. (2017) compared postmortem neuronal tissue samples from five patients with 4-18 times CE-MRI examinations by using gadodiamide as contrast agent. They found gadodiamide-exposed patients had 0.1-19.4 $\mu \mathrm{g}$ of gadolinium per gram of tissue, and gadolinium was accumulated in the neuronal interstitium and capillary endothelium, even in the cell nucleus. All the aforementioned studies only detected the gadolinium deposition in patients with linear GBCAs administrations. One study by Murata et al. (2016) evaluated whether macrocyclic chelates GBCAs might deposit in human brain. In this study, tissue samples were acquired 
TABLE 1 | Biochemical properties of gadolinium-based contrast agents currently approved for clinical use.

\begin{tabular}{|c|c|c|c|c|}
\hline Chemical structure & Trade name & $\begin{array}{l}\text { Thermodynamic } \\
\text { stability contrast }\end{array}$ & Conditional stability & Elimination pathway \\
\hline \multicolumn{5}{|l|}{ Linear } \\
\hline \multicolumn{5}{|l|}{ Nonionic } \\
\hline Gadodiamide & Omniscan & 16.8 & 14.9 & Renal \\
\hline Gadoversetamide & Optimark & 16.6 & 15 & Renal \\
\hline \multicolumn{5}{|l|}{ Ionic } \\
\hline Godopentetate dimeglumine & Magnevist & 22.1 & 17.7 & Renal \\
\hline Gadobenate dimeglumine & Multihance & 22.6 & 18.4 & 93\%Renal; 3\%Biliary \\
\hline Gadoxeticacid disodium & Primovist & 23.5 & NA & 50\%Renal; 50\%Biliary \\
\hline Gadofosveset trisodium & Multihance & 22 & NA & 91\%Renal; 9\%Biliary \\
\hline \multicolumn{5}{|l|}{ Macrocyclc } \\
\hline \multicolumn{5}{|l|}{ Nonionic } \\
\hline Gadoteridol & Prohance & 22.8 & 17.1 & Renal \\
\hline Gadobutrol & Gadavist & 21.8 & NA & Renal \\
\hline \multicolumn{5}{|l|}{ Ionic } \\
\hline Gadoterate meglumine & Dotarem & 25.4 & 19 & Renal \\
\hline
\end{tabular}

NA indicates not applicable.
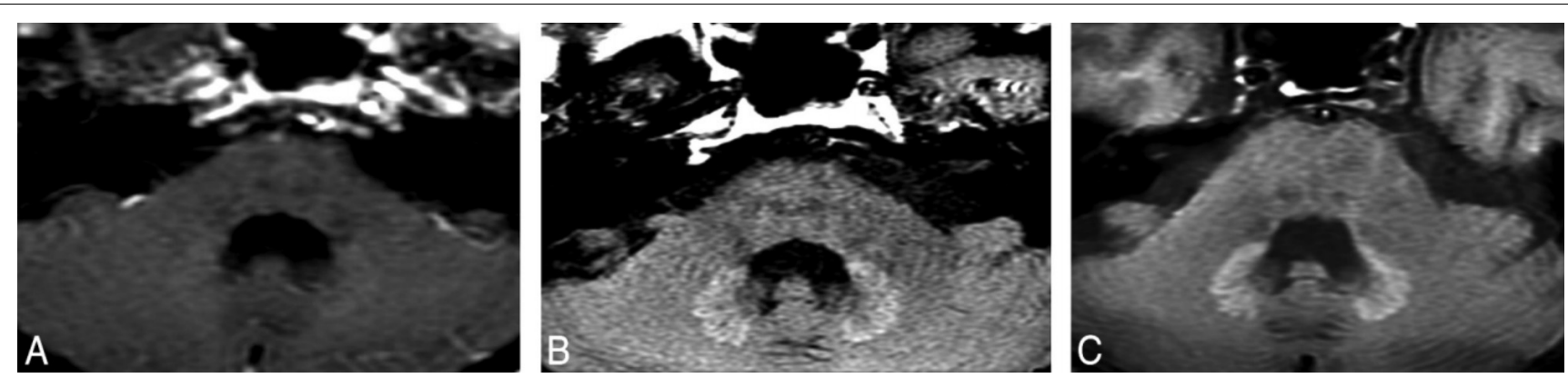

FIGURE 1 | A patient with optical nerve pilocytic astrocytoma who treated with 5400-cGy radiation therapy and underwent 25 times CE-MRI scans show hyperintensity of the DN on unenhanced T1WI. DN initially appears as slightly hyperintense (A). During the follow-up studies performed at 5 (B) and 8 (C) years after the initial hyperintense appearance of the DN, the signal intensity of the DN become more obvious. Image courtesy of Dr. Mehmet Emin Adin, Russell H. Morgan Department of Radiology, Division of Neuroradiology, Johns Hopkins Medical Institutions, Baltimore, MD. Images and text reproduced from reference 1 with written permission from AJNR.

from 9 decedents undergoing autopsy who received CEMRI examination using only single type of non-NSF related GBCAs, including gadoteridol $(n=5)$, gadobutrol $(n=2)$, gadobenate $(n=1)$, and gadoxetate $(n=1)$. They found gadolinium deposited in various brain areas including the caudate nucleus, putamen, cerebral white matter, and pons, with the highest levels in DN and GP for all patients. This finding indicated gadolinium deposition could be independent on gadolinium types. However, more evidences are needed to further confirm this finding via sensitive ICP-MS brain tissue analysis. Table 3 presents the currently available reports of gadolinium deposition in brain with histological evidences. However, changes of T1 signal intensity are non-specific and can appear in several other pathological conditions such as calcium, manganese, iron, lipid, and other substances (Ginat and Meyers, 2012), further examinations and careful analysis are needed to verify what is responsible for the $\mathrm{T} 1$ signal intensity change.

\section{THE EFFECT OF GBCAs TYPES ON THE GADOLINIUM DEPOSITION}

Although autopsy studies have shown all GBCAs can lead to gadolinium deposition in brain, most clinical studies indicated linear GBCAs had more detectable gadolinium deposition than macrocyclic GBCAs. Radbruch et al. (2015) compared signal intensity ratios of the GP and the DN to other structures on unenhanced T1WI in patients with linear chelates or macrocyclic chelates GBCAs exposure. Their study included two groups of 50 patients who received at least six consecutive MRI examinations exclusively using either a macrocyclic GBCA (gadoterate meglumine) or a linear GBCA (gadopentetate dimeglumine). They found signal intensity increase in the DN and GP on unenhanced T1WI was caused by serial application of the linear GBCAs rather than macrocyclic GBCAs. Kanda et al. (2015b) evaluated 73 patients who had previously exposed to GBCAs (23 patients received linear GBCAs, 36 patients received 
TABLE 2 | Association between CNS structures hyperintensity and GBCAs administration in human.

\begin{tabular}{|c|c|c|c|c|}
\hline Study & Groups & Contrast agent & MFS and sequence & Remarks \\
\hline \multicolumn{5}{|l|}{ Adult study } \\
\hline Kanda et al., 2014 & $\begin{array}{l}19 \text { patients underwent } \\
\text { more than } 6 \text { CE-MRI } \\
\text { examinations; } 16 \text { patients } \\
\text { underwent more than } 6 \\
\text { unenhanced examinations }\end{array}$ & $\begin{array}{l}\text { Gadopentetate-dimeglumine } \\
\text { Gadodiamide }\end{array}$ & $1.5 \mathrm{~T}$ & $\begin{array}{l}\text { High SI in the DN and GP was } \\
\text { associated with the number of } \\
\text { previous CE-MRI examinations }\end{array}$ \\
\hline Errante et al., 2014 & $\begin{array}{l}38 \text { patients with MS } \\
\text { underwent more than } 2 \\
\text { times CE-MRI scans; } 37 \\
\text { patients with brain } \\
\text { metastases underwent } \\
\text { more than } 2 \text { CE-MRI scans }\end{array}$ & Gadodiamide & 1.5T and 2-D TSE T1-weighted & $\begin{array}{l}\text { Increase signal intensity on } \\
\text { unenhanced T1WI has a linear } \\
\text { relationship with the CE-MRI in } \\
\text { patients with MS and BM }\end{array}$ \\
\hline Weberling et al., 2015 & $\begin{array}{l}50 \text { patients underwent } \\
\text { more than } 5 \text { CE-MRI }\end{array}$ & Gadobenate-dimeglumine & $\begin{array}{l}\text { 1.5T T1-weighted spin echo } \\
\text { 3.0T fast low-angle shot }\end{array}$ & $\begin{array}{l}\text { The SI ratio in the DN was } \\
\text { increased after serial } \\
\text { gadobenate dimeglumine } \\
\text { administrations }\end{array}$ \\
\hline Adin et al., 2015 & $\begin{array}{l}184 \text { patients treated with } \\
\text { brain irradiation underwent } \\
2677 \mathrm{MRI} \text { studies }\end{array}$ & $\begin{array}{l}\text { Almost exclusively } \\
\text { Gadopentetate-dimeglumine }\end{array}$ & $\begin{array}{l}1.5 \text { or } 3.0 T \text { MPRAGE, } \\
\text { Spin-echo sequence and T1WI } \\
\text { FLAIR }\end{array}$ & $\begin{array}{l}\text { Repeated CE-MRI } \\
\text { examinations likely results in } \\
\text { persistent hyperintensity in the } \\
\text { DN on unenhanced T1WI }\end{array}$ \\
\hline Zhang et al., 2017 & $\begin{array}{l}13 \text { patients with more than } \\
39 \text { chelates GBCA } \\
\text { administrations }\end{array}$ & $\begin{array}{l}\text { Gadodiamide } \\
\text { Gadopentetate-dimeglumine } \\
\text { Gadobenate }\end{array}$ & $\begin{array}{l}\text { 1.5T or 3.0T 2D spin echo } \\
\text { T1-weighted sequence 3D } \\
\text { spoiled gradient-echo volume } \\
\text { sequence }\end{array}$ & $\begin{array}{l}\text { Increased SI on unenhanced } \\
\text { T1WI was seen in the posterior } \\
\text { thalamus, substantia nigra, red } \\
\text { nucleus, cerebellar peduncle, } \\
\text { colliculi, DN, and GP }\end{array}$ \\
\hline Ramalho et al., 2016b & $\begin{array}{l}18 \text { patients with previous } \\
\text { gadodiamide and current } \\
\text { gadobenate dimeglumine } \\
\text { exposed; } 44 \text { patients with } \\
\text { only gadobenate } \\
\text { dimeglumine exposed }\end{array}$ & $\begin{array}{l}\text { Gadodiamide } \\
\text { Gadobenate-dimeglumine }\end{array}$ & $\begin{array}{l}\text { 1.5T fast spin echo } \\
\text { T1-weighted images }\end{array}$ & $\begin{array}{l}\text { Compared to those patients } \\
\text { without previously } \\
\text { gadodiamide-exposed, the } \\
\text { prior gadodiamide-exposed } \\
\text { groups show greater T1 SI } \\
\text { changed }\end{array}$ \\
\hline Kuno et al., 2017 & $\begin{array}{l}9 \text { patients received } 1-8 \\
\text { times gadopentetate } \\
\text { dimeglumine; } 26 \text { patients } \\
\text { without prior GBCA } \\
\text { exposure }\end{array}$ & Gadopentetate-dimeglumine & $\begin{array}{l}\text { 1.5T mixed fast spin echo pulse } \\
\text { sequence }\end{array}$ & $\begin{array}{l}\text { GBCA exposure patients show } \\
\text { shorter T1 value compared with } \\
\text { patients without prior GBCA } \\
\text { exposure }\end{array}$ \\
\hline \multicolumn{5}{|l|}{ Pediatrics study } \\
\hline Miller et al., 2015 & $\begin{array}{l}\text { A pediatric patient who } \\
\text { received } 35 \text { doses of linear } \\
\text { GBCA during } 12 \text { years }\end{array}$ & Gadopentetate-dimeglumine & $\begin{array}{l}\text { 1.5T T1-weighted } \\
\text { turbo-spin-echo }\end{array}$ & $\begin{array}{l}\text { The DN, GP, and posterior } \\
\text { thalamus showed visually } \\
\text { evident increase in } \\
\text { hyperintensity over the cause of } \\
\text { repeated CE-MRI scans }\end{array}$ \\
\hline $\begin{array}{l}\text { Roberts and Holden, } \\
2015\end{array}$ & $\begin{array}{l}\text { A } 13 \text { years old girl with } \\
\text { follow-up CE-MRI scans }\end{array}$ & Gadopentetate-dimeglumine & 1.5T or 3.0T & $\begin{array}{l}\text { With the increasing use of } \\
\text { GBCAs, hyperintensity was } \\
\text { noted within both the DN and } \\
\text { GP bilaterally }\end{array}$ \\
\hline Roberts et al., 2016a & $\begin{array}{l}16 \text { patients underwent } \\
\text { more than } 5 \text { consecutive } \\
\text { CE-MRI scans }\end{array}$ & Gadopentetate-dimeglumine & $\begin{array}{l}\text { 1.5T or } 3.0 \mathrm{~T} \mathrm{~T} 1 \text {-weighted } \\
\text { spin-echo } \\
\text { Sequence }\end{array}$ & $\begin{array}{l}\text { The number of prior GBCA } \\
\text { doses is significantly correlated } \\
\text { with progressive } \\
\text { T1-weighted DN hyperintensity }\end{array}$ \\
\hline Hu et al., 2016 & $\begin{array}{l}21 \text { patients received 5-37 } \\
\text { times CE-MRI scans during } \\
\text { their medical treatment; } 21 \\
\text { controls of similar age } \\
\text { without GBCA exposed }\end{array}$ & Gadopentetate-dimeglumine & $\begin{array}{l}\text { 1.5T T1 weighted 2-D fast spin } \\
\text { echo }\end{array}$ & $\begin{array}{l}\text { In all } 21 \text { patients with GBCA } \\
\text { exposed, increased SI ratios } \\
\text { were } 18.6 \% \pm 12.7 \% \text { for the } \\
\text { DN, and } 12.4 \% \pm 7.4 \% \text { for the } \\
\text { GP between the first and the } \\
\text { most recent MRI scans }\end{array}$ \\
\hline Flood et al., 2016 & $\begin{array}{l}46 \text { pediatrics patients } \\
\text { underwent more than } 3 \\
\text { times CE-MRI scans; } 57 \\
\text { age-matched GBCA-naive } \\
\text { control subjects }\end{array}$ & Gadopentetate-dimeglumine & $\begin{array}{l}\text { 1.5T T1-weighted spin-echo } \\
\text { sequence T1-weighted 3-D } \\
\text { MPRAGE sequence }\end{array}$ & $\begin{array}{l}\text { SI in the pediatric brain } \\
\text { increases on unenhanced } \\
\text { T1-weighted MRI with repeated } \\
\text { exposure to linear GBCA }\end{array}$ \\
\hline
\end{tabular}

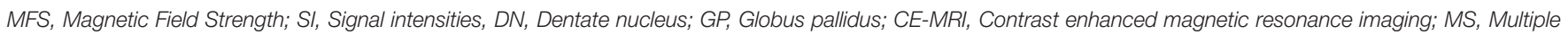
sclerosis; BM, Brain metastases; FLAIR, Fluid attenuated inversion recovery; MPRAGE, magnetization prepared rapid acquisition of gradient echo sequence. 
TABLE 3 | Autopsy studies in human or animal models.

\begin{tabular}{|c|c|c|c|c|}
\hline & Group & Contrast agent & Detection methods & Remarks \\
\hline \multicolumn{5}{|l|}{ Human study } \\
\hline McDonald et al., 2015 & $\begin{array}{l}13 \text { patients with more than } 4 \\
\text { GBCA administrations; } 10 \\
\text { patients without GBCA } \\
\text { exposed }\end{array}$ & Gadodiamide & $\begin{array}{l}\text { ICP-MS; Transmission } \\
\text { electron microscopy; Light } \\
\text { microscopy }\end{array}$ & $\begin{array}{l}\text { Gadolinium CNS structures } \\
\text { deposition was associated with } \\
\text { GBCA administrations and was } \\
\text { independently with patients } \\
\text { age, sex, renal function or } \\
\text { interval between GBCAs } \\
\text { exposed and death }\end{array}$ \\
\hline Kanda et al., 2015a & $\begin{array}{l}5 \text { patients received linear } \\
\text { GBCAs before death; } 5 \\
\text { patients with no history of } \\
\text { GBCAs exposed before death }\end{array}$ & $\begin{array}{l}\text { Gadopentetate-dimeglumine } \\
\text { Gadodiamide Gadoteridol }\end{array}$ & ICP-MS & $\begin{array}{l}\text { Gadolinium was deposited in } \\
\text { the brain even in subjects } \\
\text { without severe renal } \\
\text { dysfunction, the highest } \\
\text { accumulation area was the DN } \\
\text { and GP }\end{array}$ \\
\hline Murata et al., 2016 & $\begin{array}{l}5 \text { received gadoteridol; } 2 \\
\text { received gadobutrol; } 1 \text { received } \\
\text { gadobenate; } 1 \text { received } \\
\text { gadoxetate; } 9 \text { patients without } \\
\text { GBCAs exposed }\end{array}$ & $\begin{array}{l}\text { Gadoteridol Gadobutrol } \\
\text { Gadobenate Gadoxetate }\end{array}$ & ICP-MS & $\begin{array}{l}\text { Gadolinium was found with all } \\
\text { agents in all brain areas } \\
\text { sampled with highest levels in } \\
\text { GP and DN }\end{array}$ \\
\hline Mcdonald et al., 2017 & $\begin{array}{l}5 \text { patients underwent 4-18 } \\
\text { times CE-MRI examinations; } 10 \\
\text { patients with no history of } \\
\text { GBCAs exposed }\end{array}$ & Gadodiamide & $\begin{array}{l}\text { ICP-MS; Transmission } \\
\text { electron microscopy with } \\
\text { energy-dispersive x-ray } \\
\text { spectroscopy; Light } \\
\text { microscopy }\end{array}$ & $\begin{array}{l}\text { The patient DN, pons, GP and } \\
\text { thalamus, contained } \\
0.1-19.4 \mu \mathrm{g} \text { of gadolinium per } \\
\text { gram of tissue in intracranial } \\
\text { normality patients }\end{array}$ \\
\hline \multicolumn{5}{|l|}{ Animal models } \\
\hline Robert et al., 2015a & $\begin{array}{l}7 \text { rats with } \\
\text { gadodiamide-treated; } 7 \text { rats } \\
\text { with gadoterate; } \\
\text { meglumine-treated } 7 \text { rats with } \\
\text { hyperosmolar saline-treated }\end{array}$ & $\begin{array}{l}\text { Gadodiamide Gadoterate } \\
\text { meglumine }\end{array}$ & ICP-MS & $\begin{array}{l}\text { Repeated administration of the } \\
\text { gadodiamide but not for the } \\
\text { gadoterate meglumine were } \\
\text { associated with } \\
\text { T1-hyperintensity in the DN }\end{array}$ \\
\hline Robert et al., 2015b & $\begin{array}{l}8 \text { rats with gadobenate } \\
\text { dimeglumine-exposed; } 8 \text { rats } \\
\text { with gadopentetate } \\
\text { dimeglumine-exposed; } 8 \text { rats } \\
\text { with gadodiamide-exposed; } 8 \\
\text { rats with gadoterate; } \\
\text { meglumine-exposed } 8 \text { rats } \\
\text { control group with saline } \\
\text { injection }\end{array}$ & $\begin{array}{l}\text { Gadobenate-dimeglumine } \\
\text { Gadopentetate-dimeglumine } \\
\text { Gadodiamide } \\
\text { Gadoterate-dimeglumine }\end{array}$ & ICP-MS R1-mapping & $\begin{array}{l}\text { Linear chelates GBCAs, } \\
\text { gadodiamide, gadobenate } \\
\text { dimeglumine, gadopentetate } \\
\text { dimeglumine were associated } \\
\text { with T1 hyperintensity in the DN } \\
\text { along with gadolinium } \\
\text { deposition in the cerebellum } \\
\text { while gadoterate } \\
\text { meglumine-exposed rats with } \\
\text { no abnormal signal intensity } \\
\text { observed }\end{array}$ \\
\hline Lohrke et al., 2017 & $\begin{array}{l}10 \text { rats received gadodiamide; } \\
10 \text { rats received gadopentetate } \\
\text { dimeglumine; } 10 \text { rats received } \\
\text { gadobutrol; } 10 \text { rats received } \\
\text { gadoteridol; } 10 \text { rats received } \\
\text { saline as control group }\end{array}$ & $\begin{array}{l}\text { Gadodiamide } \\
\text { Gadopentetate-dimeglumine } \\
\text { Gadobutrol Gadoteridol }\end{array}$ & $\begin{array}{l}\text { ICP-MS; LA-ICP-MS; } \\
\text { Scanning electron } \\
\text { microscopy coupled to } \\
\text { energy dispersive } \text { x-ray } \\
\text { spectroscopy and } \\
\text { transmission electron } \\
\text { microscopy respectively }\end{array}$ & $\begin{array}{l}\text { The administration of linear } \\
\text { GBCAs was associated with } \\
\text { significant high gadolinium } \\
\text { concentration in the brain and } \\
\text { skin compared to macrocyclic } \\
\text { GBCA administration, however, } \\
\text { no histopathological findings } \\
\text { were detected in the rat's brain. }\end{array}$ \\
\hline Boyken et al., 2018 & $\begin{array}{l}8 \text { pigs received gadobutrol and } \\
\text { gadopentetate dimeglumine } 5 \\
\text { received gadobutrol only }\end{array}$ & $\begin{array}{l}\text { Gadobutrol } \\
\text { Gadopentetate-dimeglumine }\end{array}$ & ICP-MS & $\begin{array}{l}\text { Repeated gadobutrol exposure } \\
\text { is not associated with } \\
\text { gadolinium deposition in } \\
\text { healthy pigs' brain, but } \\
\text { additional a single dose } \\
\text { gadopentetate dimeglumine is } \\
\text { sufficient for gadolinium } \\
\text { accumulation in the DN and GP }\end{array}$ \\
\hline
\end{tabular}

GBCA, Gadolinium-based contrast agent; ICP-MS, Inductively coupled plasma mass spectroscopy; LA-ICP-MS, laser ablation coupled with ICP-MS; CNS, Central nervous system; DN, Dentate nucleus; GP, Globus pallidus. 
macrocyclic GBCAs, and 14 patients received both types of GBCAs) and 54 cases with no history of administrating any kind of gadolinium chelates. They found that T1-hyperintensity in the DN was related with previous use of linear GBCA (gadopentetate dimeglumine) rather than macrocyclic GBCA (gadoteridol). Gadoxetic acid, or gadoxetate disodium has been used as a liver-specific MRI contrast agent since its introduction in 2008, and there was no study showing possible brain gadolinium deposition after using gadoxetic acid. Ichikawa et al. (2017) compared 33 patients with more than 5 times of gadodiamide exposure (linear-nonionic) with 33 patients with more than 5 times of gadoxetic acid exposure (linear-ionic) and found T1-hyperintensity in the DN was related with previous gadodiamide administrations but not gadoxetic acid administrations. However, the administrated gadolinium dose in gadoxetic acid was only a quarter of that in gadodiamide, which might influence the results of this study.

Many animal studies also supported the viewpoint that linear GBCAs had more detectable gadolinium deposition in brain than macrocyclic GBCAs did (Jost et al., 2015; Robert et al., 2015a,b; Lohrke et al., 2017; Boyken et al., 2018). For example, Robert et al. (2015a) compared the signal intensity of DCN and the DN in healthy rats after exposing to some linear and macrocyclic agents. They divided 21 rats into 3 groups: gadodiamide-treated group, gadoterate meglumine-treated group and hyperosmolar saline group. This study showed repeated use of gadodiamide (linear agent) in healthy rats was related with persistent and progressive T1-hyperintensity in the DCN and gadolinium deposition in cerebellum, while in the gadoterate meglumine (macrocyclic agent) -treated group, no effect was observed. Boyken et al. (2018) collected the cerebellum, DCN, cerebral cortex, and pons of 15 pigs after repeated intravenous injections of GBCAs. Of the 15 pigs, 8 received up to 48 doses of gadobutrol and gadopentetate dimeglumine, 5 received up to 29 doses of gadobutrol only, and 2 had no GBCA administrations. After analyzing the gadolinium concentration in the aforementioned brain areas by ICP-MS, they found gadobutrol exposure was not associated with gadolinium deposition in pig brain while even a single additional administration of gadopentetate dimeglumine was sufficient for gadolinium accumulation in the DN and GP.

\section{MACROCYCLIC CHELATES GBCAs AND GADOLINIUM DEPOSITION IN HUMAN BRAIN}

Although many studies showed the linear GBCAs were associated with the gadolinium deposition in human brain, some studies indicated macrocyclic chelate GBCAs also lead to T1-hyperintensity in brain. Stojanov et al. (2016) revealed an obvious signal intensity increase in both GP and DN on unenhanced T1WI in patients with RRMS following multiple gadobutrol administrations. They divided 58 patients into 3 groups (27, 96-98, and 118 weeks) based on the intervals of contrast administrations. Patients receiving contrast agents with 27 weeks interval showed the largest increase in GP-to-thalamus signal intensity ratio, while a decrease in the GP-to-thalamus signal intensity ratio was found in patients receiving contrast agents with intervals of 96-98 weeks. However, this study did not consider other confounding factors such as other causes or disease process resulting in T1 hyperintensity, previous use of other contrast agents, and disease activity itself (Roccatagliata et al., 2009; Agris et al., 2016). Bjørnerud et al. (2017) reported two patients without any linear GBCA administrations before and received 37 and 44 doses of gadubutrol respectively, and they found visually appreciable enhancement of the DN on unenhanced T1WI, which showed a significant linear association with the number of macrocyclic GBCA injections. This finding should be further confirmed in larger and better controlled prospective studies. Based on current evidences, it suggests that both linear and macrocyclic GBCAs can cause gadolinium retention, despite the very different levels of total gadolinium exposure.

Similarly, the controversy about whether the macrocyclic chelates may induce hyperintensity in the specific brain structures in pediatrics also exists. Although many studies (Radbruch et al., 2017; Renz et al., 2017; Tibussek et al., 2017; Ryu et al., 2018) reported that only the linear chelates were associated with T1-hyperintensity in the brain while the macrocyclic chelates were not responsible for this change, some researchers also found that the administration of some macrocyclic chelates (gadoterate meglumine) was associated with T1 signal intensity changes in children (Mcr et al., 2017).

\section{GADOLINIUM DEPOSITION BEYOND THE BRAIN}

Gadolinium-based contrast agents can not only deposit in the brain, but also in the skin, bone, liver, and other organs. Gibby et al. (2004) found that gadodiamide or gadoteridol could deposit in the bones in patients undergoing total hip arthroplasty through inductivity coupled plasma atomic emission spectroscopy. Many other researchers (White et al., 2006; Darrah et al., 2009; Lord et al., 2017) confirmed this finding. There was a positive correlation between the dose of GBCAs administration and the gadolinium concentration measured in bone. It's worth mentioning that macrocyclic chelates (gadobutrol) could accumulate in the bone and retain for 5 years after one injection (Lord et al., 2017), and autopsy study (Murata et al., 2016) demonstrated gadolinium level in the bone was 23 times higher than in the brain, which suggest that bone may act as a long-term storage site for gadolinium in the body. Roberts et al. (2016b) reported gadolinium accumulation in the skin of one patient with normal renal function after exposure to 61 cumulative doses of GBCAs. Maximova et al. (2016) reported liver gadolinium deposition occurred in pediatric patients with iron overload but normal hepatic and renal function following CE-MRI examinations.

Being similar as the results in humans, the rat models (McDonald et al., 2017) showed significantly elevated levels of elemental gadolinium in hepatic, splenic, and renal tissues following administration of high doses of GBCAs, although no tissue injury was observed in these organs. 


\section{POTENTIAL PATHWAY OF GBCAS ENTERING INTO THE BRAIN}

There are two barrier systems in human brain, the blood-CSF and the BBB barrier. In normal conditions, GBCAs can not penetrate the intact $\mathrm{BBB}$ (Weinmann et al., 1984), while various illness conditions may affect $\mathrm{BBB}$ integrity and function and allow the GBCAs enter into the brain. Previous studies showed that gadolinium could deposit in the brain without intracranial abnormality (McDonald et al., 2017). Jost et al. (2015) evaluated the infiltration and distribution of 5 commercial GBCAs (gadopentetate dimeglumine, gadobenate dimeglumine, gadodiamide, gadoterate meglumine, gadobutrol) into the CSF in healthy rats. This study demonstrated the above-mentioned 3 linear chelates can increase and persist the $\mathrm{DN}$ to pons signal intensity ratios during up to 24 days observation. A CSF signal enhancement on postcontrast fluid-attenuated inversion recovery images (FLAIR) was found for all GBCAs independent of their chemical structure. Thus, the GBCAs passing from the blood into CSF might represent an initial pathway of GBCA infiltration into the brain. Nevertheless, to date, the underlying mechanism of gadolinium distribution into the DN and the GP remains unclear and needs be further studied.

\section{CLEARANCE OF GADOLINIUM FROM THE BRAIN}

Previous studies focused on the signal intensity changes on unenhanced T1WI MRI and the histological analysis on gadolinium deposition, however, few studies to date have been conducted to investigate whether those materials were cleared. The hyperintensity disappearance of the DN during follow-up was firstly described by Adin et al. (2015). After that, Smith et al. (2016) measured the gadolinium deposition level in healthy rats in 1 and 20 weeks after administrating linear chelates gadodiamide with up to 20 repeated doses. One week after dosing, gadolinium was detected in the brain at $0.00019 \%$ of the injected dose, and 20 weeks later, this diminished by approximately $50 \%$ ( $0.00011 \%$ of the injected dose). This study demonstrated partial clearance of the agents occurred over 20 weeks, however, it remains to be further confirmed in humans. Behzadi et al. (2018) conducted a retrospective study in 13 patients with previous more than 6 times gadopentetate dimeglumine (linear chelate GBCA) administrations then switching to gadobutrol (macrocyclic chelate GBCA) administrations. They found the developed DN-to-pons and DN-to-cerebellar peduncle signal intensity ratios decreased during mean follow-up time of 28 months after the last gadopentetate dimeglumine administration. The mechanism of the decreased signal intensity ratio was ascribed to the GBCAs washout hypotheses, chelators in the patient's diet or medications, or the mixture of discussed mechanisms. However, the interaction between signal intensity and repeated gadobutrol administrations during follow-up can be further studied (Adin and Yousem, 2018). As for the washout hypothesis, some researchers (Smith et al., 2016) approved the findings while other studies (McDonald et al., 2015; Robert et al., 2015b) did not demonstrate. These inconsistent results indicated that if washout occurs, maybe it is in very low level because earlier observation demonstrated no washout while longer follow-up imaging showed washout sign (Ramalho and Ramalho, 2017).

\section{POTENTIAL IMPACTS OF GBCAs ADMINISTRATIONS}

With repeated GBCAs administrations, gadolinium can deposit in brain and other organs even in patients with normal renal function. However, the clinical implication of the gadolinium deposition in the brain remains poorly understood.

Although some adverse effects of gadodiamide administration were reported, no strong evidences showed gadolinium deposition in the brain induced adverse clinical effects. Prince et al. (2011) reported gadodiamide administration caused spurious hypocalcemia, especially in patients with renal insufficiency and at doses of $0.2 \mathrm{mmol} / \mathrm{kg}$ or higher. Burke et al. (2016) did a survey about patients' self-described toxicity related to GBCAs administrations. In this study, the most common symptoms were bone/joint pain and head/neck symptoms including vision, headache and hearing change. The study had a long list of limitations such as selection bias and validity problems, but constituted the first depiction of symptoms, which may be associated with gadolinium toxicity. One study by Bussi et al. (2017) evaluated the toxic effects of single and cumulative doses of gadobenate dimeglumine in neonatal and juvenile rats after receiving either saline or gadobenate dimeglumine at doses of $0.6,1.25$, or $2.5 \mathrm{mmol} / \mathrm{kg}$. The authors reported no effects of gadobenate dimeglumine on cognitive function, behavior or any other parameters of rats, even at the highest administrated cumulative dose $(15 \mathrm{mmol} / \mathrm{kg})$. Thus, they concluded gadolinium in juvenile rat brain receiving single or cumulative gadobenate dimeglumine injection was minimal and non-impactful.

Gadolinium can deposit in the DN and GP and the potentially damaged GP may induce Parkinsonian symptoms. Welk et al. (2016) performed a population-based study to assess the relationship between parkinsonism and gadolinium exposure. In this study, 246557 patients underwent at least one MRI examination during the study, there were 99739 patients receiving at least one dose of gadolinium, and 2446 patients receiving 4 or more CE-MRI examinations. The results demonstrated the incident parkinsonism developed in $1.17 \%$ of gadolinium exposed patients and $1.16 \%$ of unexposed patients, and no significant association between parkinsonism and gadolinium exposure and parkinsonism was discovered. Perrotta et al. (2017) performed a retrospective study about the clinical cerebellar syndrome caused by gadoterate administration in ten patients who had previously received more than 20 doses of gadoterate. During 91-month follow-up, neither appearance of a rising cerebellar syndrome nor newly appeared symptoms or signs suggesting cerebellar toxicity were reported by the clinician. 


\section{POTENTIAL CONFOUNDING VARIABLES ON GADOLINIUM DEPOSITION IN BRAIN}

\section{Renal Function}

Due to the majority of GBCAs excretion through the kidney, the researchers firstly concerned about the impact of renal function on the gadolinium deposition. Kanda et al. (2015a) analyzed brain tissues of 5 subjects and found out GBCAs accumulated in brain of subjects without severe renal dysfunction. Thus, even if the patient has normal renal function, GBCAs can still deposit in the human body. In patients with renal dysfunction, the condition of gadolinium accumulation in the body remains poorly understood. Kartamihardja et al. (2016) found renal dysfunction increased short-term gadolinium deposition in the bone, liver, skin, spleen, and kidney but it did not impact long-term gadolinium deposition. Rahatli et al. (2018) compared 13 patients on chronic hemodialysis who underwent $78 \mathrm{CE}-\mathrm{MRI}$ examinations with linear chelates GBCA (gadoversetamid) administrations with 13 patients with normal renal function, and they found the gadolinium accumulation rate in the brain after linear GBCA exposure may be affected by renal function. So, only in necessary conditions, GBCAs should be used and stabilized forms should be preferred.

\section{PATIENTS' DISEASE CONDITION}

\section{Multiple Sclerosis}

Multiple sclerosis patients need undergo brain MRI examinations both during periods of relapse and remission (every few months) to evaluate disease activity. The DN T1 hyperintensity was observed in patients with multiple sclerosis (Roccatagliata et al., 2009; Agris et al., 2016). This T1 hyperintensity was attributed to clinical disability, lesion load and brain atrophy (Rahatli et al., 2018), but not GBCAs administrations. Therefore, multiple sclerosis patients have been excluded from most investigations studying brain GBCAs deposition. However, some studies about the influence of different types of GBCAs administrations on gadolinium deposition were conducted in patients with MS and came to different results. In these studies, some researchers (Stojanov et al., 2016) reported DN-to-pons signal intensity ratios increased after repeated macrocyclic GBCAs administrations, while other researchers (Schlemm et al., 2016; Splendiani et al., 2017) concluded that multiple doses macrocyclic chelates administrations were not related to brain signal intensity changes in multiple sclerosis patients.

It appears disease spectrum has been associated with gadolinium deposition in human. One study (Tanaka et al., 2016) compared the gadolinium deposition difference between NMOSD patients and multiple sclerosis patients, and they showed patients with multiple sclerosis were prone to gadolinium accumulation while NMOSD patients had less tendency. The authors believed the differences in disease pathology and structure of gadolinium might impact gadolinium deposition.

\section{BRAIN IRRADIATION}

Radiation-related brain injury may lead to calcifications, which can present as high signal intensity on the T1WI (Suzuki et al., 2000). Therefore, patients who have experienced brain irradiation are usually excluded from the studies investigating the relation of hyperintensity signal changes with previous administration of gadolinium. Tamrazi et al. (2017) observed 144 pediatric patients with CE-MRI examinations, including 55 patients with primary brain tumors and whole-brain irradiation, 19 with primary brain tumors and chemotherapy only, 52 with primary brain tumors without any treatments, and 18 with neuroblastoma without brain metastatic disease. This study demonstrated that at fewer numbers of GBCAs administration ( $\leq 10$ times), whole-brain irradiation seemed to play a greater role in increasing the T1 signal intensity on unenhanced T1WI than administered GBCAs, while at a higher number of GBCAs administration ( $\geq 20$ times), GBCAs seemed to contribute more to the increased signal intensity.

\section{MAGNETIC FIELD STRENGTH, MRI SEQUENCE AND INTERVAL TIME BETWEEN EXAMINATIONS}

Although many gadolinium deposition studies have been published, one major limitation of these studies is the variability of the MR imaging protocols. One study showed magnetic field strength might affect the T1 signal intensity, however, magnetic field strength did not change the reader's final diagnosis in any of the cases (Adin et al., 2015). Pulse sequence may directly or indirectly affect the detectability of T1 hyperintensity in the brain. Ramalho et al. (2016a) evaluated the T1 hyperintensity using spin echo (SE) sequence and magnetization prepared rapid gradient echo (MPRAGE) sequence and the result showed the DN/MCP signal intensity ratios were significantly higher when using SE than MPRAGE sequence. Thus, the two sequences should not be used interchangeably, and the baseline and final signal intensity ratios should be assessed by the same sequence. They recommended MPRAGE sequence as a simple screening tool in clinical practice for assessing patients with multiple GBCA exposure because of its intrinsic higher gray-white matter contrast. The interval time between baseline and final MRI examination (range: 96-1905 days) did not influence the final observation between the two sequences.

\section{REGULATORY STATEMENTS}

Since the first report of gadolinium deposition in brain, many official regulatory statements have been published to warn the safe use of GBCAs. In 2017, the International Society of Magnetic Resonance in Medicine (ISMRM) Safety Committee claimed that no direct evidences from human beings or animal studies demonstrated any harmful effects related to the gadolinium deposition in the brain. However, several recommendations for the use of GBCAs in clinics and research were provided by 
ISMRM. The main recommendations are as follows: (1) The ISMRM urges caution in the use of gadolinium-based contrast agents, and GBCAs should not be used when not necessary; (2) The clinical indication and pertinent information about GBCAs administrations should be documented in the patient's medical record; (3) When choosing a gadolinium-based contrast agent, many factors should be considered, including pharmacokinetics, efficacy, relaxivity, patient age, potential side effects (like allergic reactions), probability of the need for repeated examinations, and cost. Institutions should evaluate these factors and consider that some agents might be with a greater propensity for deposition than others (Gulani et al., 2017).

In December 19, 2017, the US Food and Drug Administration (FDA) reviewed available data about the gadolinium retention from GBCAs as part of its role in monitoring the post-market safety of drugs. They recommended that health care professionals should evaluate the retention characteristics of each agent when using a GBCA in patients with higher risk, such as those who may require repeated GBCA MRI scans to monitor a chronic condition. The FDA also stated as "a class-wide warning about gadolinium retention in the labeling of GBCAs and a new medication guide that should be presented to patients in advance of receiving a GBCA" (U.S. Food and Drug Administration, 2017).

The Pharmacovigilance Risk Assessment Committee (PRAC) of the European Medicines Agency (EMA) confirmed (European Medicines Agency, 2017) restrictions on using linear gadolinium agents from July 7, 2017, the PRAC recommended that the intravenous linear agents gadobenic acid and gadoxetic acid should only be used for liver scans when they meet an important diagnostic need. Additionally, gadopentetic acid should only be applied for joint scans because the gadolinium concentration in the formulation used for joint injections is very low. All other intravenous linear agents (gadoversetamide adopentetic acid, and gadodiamide) should be suspended in line with the PRAC's March 2017 recommendation. Another kind of gadolinium agent known as macrocyclic agents (gadoteric acid, gadobutrol, and gadoteridol) is more stable and has a lower tendency to release gadolinium than linear agents. These can continue to be applied in their current indications but at the lowest doses that enhance images sufficiently and only when unenhanced body scans are not appropriate.

\section{REFERENCES}

Adin, M. E., Kleinberg, L., Vaidya, D., Zan, E., Mirbagheri, S., and Yousem, D. M. (2015). Hyperintense dentate nuclei on T1-weighted MRI: relation to repeat gadolinium administration. AJNR Am. J. Neuroradiol. 36, 1859-1865. doi: 10.3174/ajnr.A4378

Adin, M. E., and Yousem, D. M. (2018). Disappearance of T1-weighted MRI hyperintensity in dentate nuclei of individuals with a history of repeat gadolinium administration. Radiology 288, 911-912. doi: 10.1148/radiol. 2018180968

Agris, J., Pietsch, H., and Balzer, T. (2016). What evidence is there that gadobutrol causes increasing signal intensity within the dentate nucleus and globus pallidus on unenhanced T1W MRI in patients with RRMS? Eur. Radiol. 26, 816-817. doi: 10.1007/s00330-015-4019-2

\section{FUTURE PERSPECTIVES}

Although rapidly increasing number of published articles, the knowledge on gadolinium deposition in the brain and its clinical significance is still insufficient. And there exist many unsolved problems and further studies are needed. Firstly, whether the deposited gadolinium in the brain may result in any clinical consequences unreported during periods of study observation. Large prospective randomized controlled trial should be performed to clarify this important issue. Secondly, the mechanism of GBCA deposition in the brain remains unknown, and several related problems are still unsolved, including the initial pathway of gadolinium entering into the brain, the potential saturation and washout effects, and the exact molecular structure of residual gadolinium. Thirdly, the mechanism of disease itself affecting the gadolinium deposition in the brain is still unknown. Are some groups of patients prone to gadolinium deposition in brain? Future studies should focus on these unsolved problems and give valid evidences to the public.

\section{CONCLUSION}

Recently studies have confirmed gadolinium accumulation in human brain following repeated gadolinium based contrast agent administrations, regardless of an intact $\mathrm{BBB}$ or normal renal function. Linear chelates GBCAs can result in more gadolinium deposition than macrocyclic chelates GBCAs. However, the impact of the retained gadolinium in the brain remains unknown, which needs large prospective studies to clarify in future. It is recommended to take caution when using macrocyclic chelates GBCAs and keep as low doses as possible for reducing gadolinium accumulation in brain.

\section{AUTHOR CONTRIBUTIONS}

All authors listed have made a substantial, direct and intellectual contribution to the work, and approved it for publication.

Behzadi, A. H., Farooq, Z., Zhao, Y., Shih, G., and Prince, M. R. (2018). Dentate nucleus signal intensity decrease on T1-weighted MR images after switching from gadopentetate dimeglumine to gadobutrol. Radiology 287, 816-823. doi: 10.1148/radiol.2018171398

Bjørnerud, A., Vatnehol, S., Larsson, C., Duetønnessen, P., Hol, P. K., and Groote, I. R. (2017). Signal enhancement of the dentate nucleus at unenhanced MR imaging after very high cumulative doses of the macrocyclic gadolinium-based contrast agent gadobutrol: an observational study. Radiology 285, 434-444. doi: 10.1148/radiol.2017170391

Boyken, J., Frenzel, T., Lohrke, J., Jost, G., and Pietsch, H. (2018). Gadolinium accumulation in the deep cerebellar nuclei and globus pallidus after exposure to linear but not macrocyclic gadolinium-based contrast agents in a retrospective pig study with high similarity to clinical conditions. Invest. Radiol. 53, 278-285. doi: $10.1097 /$ rli.0000000000000440 
Burke, L. M., Ramalho, M., Alobaidy, M., Chang, E., Jay, M., and Semelka, R. C. (2016). Self-reported gadolinium toxicity: a survey of patients with chronic symptoms. Magn. Reson. Imaging 34, 1078-1080. doi: 10.1016/j.mri.2016.05.005

Bussi, S., Penard, L., Bonafè, R., Botteron, C., Celeste, R., Coppo, A., et al. (2017). Non-clinical assessment of safety and gadolinium deposition after cumulative administration of gadobenate dimeglumine (multihance ${ }^{\circledR}$ ) to neonatal and juvenile rats. Regul. Toxicol. Pharmacol. 92, 268-277. doi: 10.1016/j.yrtph.2017. 12.016

Darrah, T. H., Prutsman-Pfeiffer, J. J., Poreda, R. J., Ellen, C. M., Hauschka, P. V., and Hannigan, R. E. (2009). Incorporation of excess gadolinium into human bone from medical contrast agents. Metallomics 1, 479-488. doi: 10 . 1039/b905145g

Dekkers, I. A., Roos, R., and Van, A. D. M. (2017). Gadolinium retention after administration of contrast agents based on linear chelators and the recommendations of the european medicines agency. Eur. Radiol. 28, 1579-1584. doi: 10.1007/s00330-0175065-8

Errante, Y., Cirimele, V., Mallio, C. A., Di, L. V., Zobel, B. B., and Quattrocchi, C. C. (2014). Progressive increase of T1 signal intensity of the dentate nucleus on unenhanced magnetic resonance images is associated with cumulative doses of intravenously administered gadodiamide in patients with normal renal function, suggesting dechelation. Invest. Radiol. 49, 685-690. doi: 10.1097/RLI. 0000000000000072

European Medicines Agency (2017). EMA's Final Opinion Confirms Restrictions on Use of Linear Gadolinium Agents in Body Scans. Available at: http://www.ema.europa.eu/docs/en_GB/document_library/Press_release/2017/ 07/WC500231829.pdf

Flood, T. F., Stence, N. V., Maloney, J. A., and Mirsky, D. M. (2016). Pediatric brain: repeated exposure to linear gadolinium-based contrast material is associated with increased signal intensity at unenhanced T1-weighted MR imaging. Radiology 282, 222-228. doi: 10.1148/radiol.2016160356

Frenzel, T., Lengsfeld, P., Schirmer, H., Hütter, J., and Weinmann, H. J. (2008). Stability of gadolinium-based magnetic resonance imaging contrast agents in human serum at 37 degrees c. Invest. Radiol. 43, 817-828. doi: 10.1097/RLI. 0b013e3181852171

Gibby, W. A., Gibby, K. A., and Gibby, W. A. (2004). Comparison of Gd DTPABMA (Omniscan) versus Gd HP-DO3A (ProHance) retention in human bone tissue by inductively coupled plasma atomic emission spectroscopy. Invest. Radiol. 39, 138-142.

Ginat, D. T., and Meyers, S. P. (2012). Intracranial lesions with high signal intensity on T1-weighted MR images: differential diagnosis. Radiographics 32, 499-516. doi: $10.1148 /$ rg.322105761

Gulani, V., Calamante, F., Shellock, F. G., Kanal, E., and Reeder, S. B. (2017). Gadolinium deposition in the brain: summary of evidence and recommendations. Lancet Neurol. 16, 564-570. doi: 10.1016/S1474-4422(17) 30158-8

Hu, H. H., Pokorney, A., Towbin, R. B., and Miller, J. H. (2016). Increased signal intensities in the dentate nucleus and globus pallidus on unenhanced T1weighted images: evidence in children undergoing multiple gadolinium MRI exams. Pediatr. Radiol. 46, 1590-1598. doi: 10.1007/s00247-016-3646-3

Ichikawa, S., Motosugi, U., Omiya, Y., and Onishi, H. (2017). Contrast agentinduced high signal intensity in dentate nucleus on unenhanced T1-weighted images: comparison of gadodiamide and gadoxetic acid. Invest. Radiol. 52, 389-395. doi: 10.1097/RLI.0000000000000360

Jost, G., Lenhard, D. C., Sieber, M. A., Lohrke, J., Frenzel, T., and Pietsch, H. (2015). Signal increase on unenhanced t1-weighted images in the rat brain after repeated, extended doses of gadolinium-based contrast agents: comparison of linear and macrocyclic agents. Invest. Radiol. 51, 83-89. doi: 10.1097/rli. 0000000000000242

Kanda, T., Fukusato, T., Matsuda, M., Toyoda, K., Oba, H., Kotoku, J., et al. (2015a). Gadolinium-based contrast agent accumulates in the brain even in subjects without severe renal dysfunction: evaluation of autopsy brain specimens with inductively coupled plasma mass spectroscopy. Radiology 276, 228-232. doi: 10.1148/radiol.2015142690

Kanda, T., Osawa, M., Oba, H., Toyoda, K., Kotoku, J., Haruyama, T., et al. (2015b). High signal intensity in dentate nucleus on unenhanced T1-weighted MR images: association with linear versus macrocyclic gadolinium chelate administration. Radiology 275, 803-809. doi: 10.1148/radiol.14140364

Kanda, T., Ishii, K., Kawaguchi, H., Kitajima, K., and Takenaka, D. (2014). High signal intensity in the dentate nucleus and globus pallidus on unenhanced T1-weighted MR images: relationship with increasing cumulative dose of a gadolinium-based contrast material. Radiology 270, 834-841. doi: 10.1148/ radiol.13131669

Kartamihardja, A. A., Nakajima, T., Kameo, S., Koyama, H., and Tsushima, Y. (2016). Impact of impaired renal function on gadolinium retention after administration of gadolinium-based contrast agents in a mouse model. Invest. Radiol. 51, 655-660. doi: 10.1097/RLI.000000000000 0295

Kasahara, S., Miki, Y., Kanagaki, M., Yamamoto, A., Mori, N., Sawada, T., et al. (2011). Hyperintense dentate nucleus on unenhanced T1-weighted MR images is associated with a history of brain irradiation. Radiology 258, 222-228. doi: $10.1148 /$ radiol. 10100508

Kim, T. J., Kim, I. O., Kim, W. S., Cheon, J. E., Moon, S. G., Kwon, J. W., et al. (2006). MR imaging of the brain in wilson disease of childhood: findings before and after treatment with clinical correlation. Am. J. Neuroradiol. 27, 1373-1378.

Kuno, H., Jara, H., Buch, K., Qureshi, M. M., Chapman, M. N., and Sakai, O. (2017). Global and regional brain assessment with quantitative MR imaging in patients with prior exposure to linear gadolinium-based contrast agents. Radiology 283, 195-204. doi: 10.1148/radiol.2016160674

Lohrke, J., Frisk, A. L., Frenzel, T., Schöckel, L., Rosenbruch, M., Jost, G., et al. (2017). Histology and gadolinium distribution in the rodent brain after the administration of cumulative high doses of linear and macrocyclic gadolinium-based contrast agents. Invest. Radiol. 52, 324-333. doi: 10.1097/rli. 0000000000000344

Lord, M. L., Chettle, D. R., Gräfe, J. L., Noseworthy, M. D., and Mcneill, F. E. (2017). Observed deposition of gadolinium in bone using a new noninvasive in vivo biomedical device: results of a small pilot feasibility study. Radiology 287, 96-103. doi: 10.1148/radiol.2017171161

Marckmann, P., Skov, L., Rossen, K., Dupont, A., Damholt, M. B., Heaf, J. G., et al. (2006). Nephrogenic systemic fibrosis: suspected causative role of gadodiamide used for contrast-enhanced magnetic resonance imaging. J. Am. Soc. Nephrol. 17, 2359-2362. doi: 10.1681/ASN.2006060601

Maximova, N., Gregori, M., Zennaro, F., Sonzogni, A., Simeone, R., and Zanon, D. (2016). Hepatic gadolinium deposition and reversibility after contrast agent-enhanced $\mathrm{mr}$ imaging of pediatric hematopoietic stem cell transplant recipients. Radiology 281:152846. doi: 10.1148/radiol.201615 2846

McDonald, R. J., McDonald, J. S., Dai, D., Schroeder, D., Jentoft, M. E., Murray, D. L., et al. (2017). Comparison of gadolinium concentrations within multiple rat organs after intravenous administration of linear versus macrocyclic gadolinium chelates. Radiology 285, 536-545. doi: 10.1148/radiol.201716 1594

McDonald, R. J., McDonald, J. S., Kallmes, D. F., Jentoft, M. E., Murray, D. L., Thielen, K. R., et al. (2015). Intracranial gadolinium deposition after contrastenhanced MR imaging. Radiology 275, 772-782. doi: 10.1148/radiol.151 50025

Mcdonald, R. J., Mcdonald, J. S., Kallmes, D. F., Jentoft, M. E., Paolini, M. A., and Murray, D. L. (2017). Gadolinium deposition in human brain tissues after contrast-enhanced MR imaging in adult patients without intracranial abnormalities. Radiology 285, 546-554. doi: 10.1148/radiol.20171 61595

Mcr, E., Bernardi, B., Pasquini, L., Figà-Talamanca, L., Tomà, P., and Napolitano, A. (2017). Erratum to: signal intensity at unenhanced t1-weighted magnetic resonance in the globus pallidus and dentate nucleus after serial administrations of a macrocyclic gadolinium-based contrast agent in children. Pediatr. Radiol. 47:1366. doi: 10.1007/s00247-017-3874-1

Miller, J. H., Hu, H. H., Pokorney, A., Cornejo, P., and Towbin, R. (2015). MRI brain signal intensity changes of a child during the course of 35 gadolinium contrast examinations. Pediatrics 136, e1637-e1640. doi: 10.1542/peds.20152222

Murata, N., Gonzalezcuyar, L. F., Murata, K., Fligner, C., and Dills, R. (2016). Macrocyclic and other non-group 1 gadolinium contrast agents deposit low levels of gadolinium in brain and bone tissue: preliminary results from 9 
patients with normal renal function. Invest. Radiol. 51, 447-453. doi: 10.1097/ RLI.0000000000000252

Perrotta, G., Metens, T., Absil, J., Lemort, M., and Manto, M. (2017). Absence of clinical cerebellar syndrome after serial injections of more than 20 doses of gadoterate, a macrocyclic gbca: a monocenter retrospective study. J. Neurol. 264, 2277-2283. doi: 10.1007/s00415-0178631-8

Prince, M. R., Zhang, H., Zou, Z., Staron, R. B., and Brill, P. W. (2011). Incidence of immediate gadolinium contrast media reactions. AJR Am. J. Roentgenol. 196, W138-W143. doi: 10.2214/ajr.10.4885

Radbruch, A., Haase, R., Kickingereder, P., Bäumer, P., and Bickelhaupt, S. (2017). Pediatric brain: no increased signal intensity in the dentate nucleus on unenhanced T1-weighted MR images after consecutive exposure to a macrocyclic gadolinium-based contrast agent. Radiology 283, 828-836. doi: 10.1148/radiol.2017162980

Radbruch, A., Weberling, L. D., Kieslich, P. J., Eidel, O., and Burth, S. (2015). Gadolinium retention in the dentate nucleus and globus pallidus is dependent on the class of contrast agent. Radiology 275, 783-791. doi: 10.1148/radiol. 2015150337

Rahatli, F. K., Donmez, F. Y., Kibaroglu, S., Kesim, C., and Haberal, K. M. (2018). Does renal function affect gadolinium deposition in the brain? Eur. J. Radiol. 104, 33-37. doi: 10.1016/j.ejrad.2018.04.017

Ramalho, J., and Ramalho, M. (2017). Gadolinium deposition, and chronic toxicity[J]. Magn. Reson. Imaging Clin. N. Am. 25, 765-778. doi: 10.1016/j.mric. 2017.06.007

Ramalho, J., Ramalho, M., Alobaidy, M., Nunes, R. H., Castillo, M., and Semelka, R. C. (2016a). T1 signal-intensity increase in the dentate nucleus after multiple exposures to gadodiamide: intraindividual comparison between 2 commonly used sequences. AJNR Am. J. Neuroradiol. 37, 1427-1431. doi: 10.3174/ajnr. A 4757

Ramalho, J., Semelka, R. C., Alobaidy, M., Ramalho, M., Nunes, R. H., and Castillo, M. (2016b). Signal intensity change on unenhanced T1-weighted images in dentate nucleus following gadobenate dimeglumine in patients with and without previous multiple administrations of gadodiamide. Eur. Radiol. 26, 4080-4088. doi: 10.1007/s00330-016-4269-7

Renz, D. M., Kümpel, S., Böttcher, J., Pfeil, A., Streitparth, F., Waginger, M., et al. (2017). Comparison of unenhanced T1-weighted signal intensities within the dentate nucleus and the globus pallidus after serial applications of gadopentetate dimeglumine versus gadobutrol in a pediatric population. Invest. Radiol. 53, 119-127. doi: 10.1097/RLI.000000000000 0419

Robert, P., Lehericy, S., Grand, S., Violas, X., Fretellier, N., Idée, J. M., et al. (2015a). T1-weighted hypersignal in the deep cerebellar nuclei after repeated administrations of gadolinium-based contrast agents in healthy rats: difference between linear and macrocyclic agents. Invest. Radiol. 2015 50, 473-480. doi: 10.1097/rli.0000000000000181

Robert, P., Violas, X., Grand, S., Lehericy, S., and Idée, J. M. (2015b). Linear gadolinium-based contrast agents are associated with brain gadolinium retention in healthy rats. Invest. Radiol. 51, 73-82. doi: 10.1097/rli. 0000000000000241

Roberts, D. R., Chatterjee, R., Yazdani, M., Marebwa, B., and Brown, T. (2016a). Pediatric patients demonstrate progressive T1-weighted hyperintensity in the dentate nucleus following multiple doses of gadolinium-based contrast agent. AJNR Am. J. Neuroradiol. 37, 2340-2347. doi: 10.3174/ajnr. A4891

Roberts, D. R., and Holden, K. R. (2015). Progressive increase of T1 signal intensity in the dentate nucleus and globus pallidus on unenhanced T1weighted MR images in the pediatric brain exposed to multiple doses of gadolinium contrast. Brain Dev. 38, 331-336. doi: 10.1016/j.braindev.2015. 08.009

Roberts, D. R., Lindhorst, S. M., Welsh, C. T., Maravilla, K. R., and Herring, M. N. (2016b). High levels of gadolinium deposition in the skin of a patient with normal renal function. Invest. Radiol. 51, 280-289. doi: 10.1097/RLI. 0000000000000266

Roccatagliata, L., Vuolo, L., Bonzano, L., Pichiecchio, A., and Mancardi, G. L. (2009). Multiple sclerosis: hyperintense dentate nucleus on unenhanced T1-weighted MR images is associated with the secondary progressive subtype. Radiology 251, 503-510. doi: 10.1148/radiol.251108 1269

Rogosnitzky, M., and Branch, S. (2016). Gadolinium-based contrast agent toxicity: a review of known and proposed mechanisms. Biometals 29, 365-376. doi: 10.1007/s10534-016-9931-7

Rovira, A., Alonso, J., and Córdoba, J. (2008). MR imaging findings in hepatic encephalopathy. AJNR Am. J. Neuroradiol. 29, 1612-1621. doi: 10.3174/ajnr. a1139

Ryu, Y. J., Choi, Y. H., Cheon, J. E., Lee, W. J., Park, S., and Kim, W. S. (2018). Pediatric brain: gadolinium deposition in dentate nucleus and globus pallidus on unenhanced T1-weighted images is dependent on the type of contrast agent. Invest. Radiol. 53, 246-255. doi: 10.1097/RLI.000000000000 0436

Schlemm, L., Chien, C., Bellmannstrobl, J., Dörr, J., Wuerfel, J., and Brandt, A. U. (2016). Gadopentetate but not gadobutrol accumulates in the dentate nucleus of multiple sclerosis patients. Mult. Scler. 23, 963-972. doi: 10.1177/ 1352458516670738

Smith, A. P., Marino, M., Roberts, J., Crowder, J. M., Castle, J., and Lowery, L. (2016). Clearance of gadolinium from the brain with no pathologic effect after repeated administration of gadodiamide in healthy rats: an analytical and histologic study. Radiology 282, 743-751. doi: 10.1148/radiol.201616 0905

Splendiani, A., Perri, M., Marsecano, C., Vellucci, V., and Michelini, G. (2017). Effects of serial macrocyclic-based contrast materials gadoterate meglumine and gadobutrol administrations on gadolinium-related dentate nuclei signal increases in unenhanced T1-weighted brain: a retrospective study in 158 multiple sclerosis (MS) patients. Radiol. Med. 123, 432-433. doi: 10.1007/ s11547-017-0816-9

Stojanov, D. A., Aracki-Trenkic, A., Vojinovic, S., Benedeto-Stojanov, D., and Ljubisavljevic, S. (2016). Increasing signal intensity within the dentate nucleus and globus pallidus on unenhanced T1W magnetic resonance images in patients with relapsing-remitting multiple sclerosis: correlation with cumulative dose of a macrocyclic gadolinium-based contrast agent, gadobutrol. Eur. Radiol. 26, 807-815. doi: 10.1007/s00330-0153879-9

Suzuki, S., Nishio, S., Takata, K., Morioka, T., and Fukui, M. (2000). Radiationinduced brain calcification: paradoxical high signal intensity in T1-weighted MR images. Acta Neurochir. 142, 801-804.

Tamrazi, B., Nguyen, B., Liu, C. J., Azen, C. G., and Nelson, M. B. (2017). Changes in signal intensity of the dentate nucleus and globus pallidus in pediatric patients: impact of brain irradiation and presence of primary brain tumors independent of linear gadolinium-based contrast agent administration. Radiology 287, 452-460. doi: 10.1148/radiol.2017171850

Tanaka, M., Nakahara, K., and Kinoshita, M. (2016). Increased signal intensity in the dentate nucleus of patients with multiple sclerosis in comparison with neuromyelitis optica spectrum disorder after multiple doses of gadolinium contrast. Eur. Neurol. 75, 195-198. doi: 10.1159/00044 5431

Tibussek, D., Rademacher, C., Caspers, J., Turowski, B., and Schaper, J. (2017). Gadolinium brain deposition after macrocyclic gadolinium administration: a pediatric case-control study. Radiology 285, 223-230. doi: 10.1148/radiol. 2017161151

U.S. Food and Drug Administration. (2017). FDA Warns that Gadolinium Based Contrast Agents (GBCAs) are Retained in the Body; Requires New Class Warnings. Available at: https://www.fda.gov/downloads/Drugs/DrugSafety/ UCM589442

Weberling, L. D., Kieslich, P. J., Kickingereder, P., Wick, W., Bendszus, M., and Schlemmer, H. P. (2015). Increased signal intensity in the dentate nucleus on unenhanced T1-weighted images after gadobenate dimeglumine administration. Invest. Radiol. 50, 743-748. doi: 10.1097/RLI. 0000000000000206

Weinmann, H. J., Brasch, R. C., Press, W. R., and Wesbey, G. E. (1984). Characteristics of gadolinium-DTPA complex: a potential nmr contrast agent. AJR Am. J. Roentgenol. 142, 619-624. doi: 10.2214/ajr.142.3.619

Welk, B., Mcarthur, E., Morrow, S. A., Macdonald, P., Hayward, J., and Leung, A. (2016). Association between gadolinium contrast exposure and the risk of parkinsonism. JAMA 316, 96-98. doi: 10.1001/jama.2016.8096 
White, G. W., Gibby, W. A., and Tweedle, M. F. (2006). Comparison of gd(dtpabma) (omniscan) versus $\operatorname{gd}(\mathrm{hp}-\mathrm{do} 3 \mathrm{a})$ (prohance) relative to gadolinium retention in human bone tissue by inductively coupled plasma mass spectroscopy. Invest. Radiol. 41, 272-278. doi: 10.1097/01.rli.0000186569. 32408.95

Zhang, Y., Cao, Y., Shih, G. L., Hecht, E. M., and Prince, M. R. (2017). Extent of signal hyperintensity on unenhanced T1-weighted brain MR images after more than 35 administrations of linear gadolinium-based contrast agents. Radiology 282, 516-525. doi: 10.1148/radiol.201615 2864
Conflict of Interest Statement: The authors declare that the research was conducted in the absence of any commercial or financial relationships that could be construed as a potential conflict of interest.

Copyright (c) 2018 Guo, Yang and Zhang. This is an open-access article distributed under the terms of the Creative Commons Attribution License (CC BY). The use, distribution or reproduction in other forums is permitted, provided the original author(s) and the copyright owner(s) are credited and that the original publication in this journal is cited, in accordance with accepted academic practice. No use, distribution or reproduction is permitted which does not comply with these terms. 